\title{
Narcisa Amália: 1852-1924. Estudo, antologia e bibliografia, por Anna Faedrich.
}

Lisboa: Biblioteca Nacional de Portugal; CLEPUL (Centro de Literaturas e Culturas Lusófonas e Europeias); CICS. NOVA (Centro Interdisciplinar de Ciências Sociais), 2020.

Ana Lisboa de Mello PPGLEN/ UFRJ - CNPq

DoI

https://doi.org/10.37508/rcl.2021.n46a470

Organizado por Anna Faedrich ${ }^{1}$ e publicado pela Biblioteca Nacional de Portugal (BNP), na "Série Senhoras do Almanaque", em 2020, o volume dedicado à escritora Narcisa Amália é resultado de parceria do Centro de Literaturas e Culturas Lusófonas e Europeias (CLEPUL), da Faculdade de Letras da Universidade de Lisboa, com o Centro Interdisciplinar de Ciências Sociais (CICS.NOVA), da Faculdade de Ciências Sociais e Humanas da Universidade Nova de Lisboa. A investigação, que está na base desta coletânea, tem por escopo divulgar a produção de escritoras no Almanaque de lembranças, Almanaque de lembranças luso-brasileiro e Novo almana-

1 Professora do Instituto de Letras da Universidade Federal Fluminense. 
que de lembranças luso-brasileiro, anuários que circularam de 1850 a 1931, nos países lusófonos.

Dada as dificuldades de as escritoras encontrarem espaços para divulgarem os seus textos no decorrer do século XIX e início do século XX, Narcisa Amália², nascida no Estado do Rio de Janeiro, em 1852, publicou um único livro em vida: a reunião de poemas intitulada Nebulosas ${ }^{3}$, editada em 1872, pela Garnier e não custeada pela autora. Segundo Ubiratan Machado, o "mérito do livro justificou a audácia do editor..." (MACHADO,2001, p.261), comentário retomado por Anna Faedrich no capítulo intitulado “Estudo”. Entre os temas dessa obra estão a identidade nacional, a natureza, a infância da escritora em Resende (RJ), o amor à Pátria e o antiescravismo. Este último tema está contemplado, na Antologia, nos poemas "O africano e o poeta" e "Perfil de escrava".

As epígrafes dos poemas, excertos de grandes clássicos da literatura universal, em várias línguas, evidenciam a erudição de Narcisa Amália. Críticos da época, entre os quais Sílvio Romero e Machado de Assis, reconheceram o talento da escritora fluminense, mas ela também foi vítima de calúnias, entre as quais a de que não era autora de Nebulosas, mas, sim, assinava poemas de um escritor que preferiu se manter no anonimato. Por trás dessa calúnia, estava a ideia de que o livro da poetisa fluminense era de uma qualidade tal que não poderia ter sido escrito por uma mulher. Essa calúnia foi definitivamente desmentida, após consistente pesquisa bibliográfica desenvolvida e publicada por Antônio Simões dos Reis (Cf. REIS, 1949).

A escritora colaborou em diversos jornais e revistas do estado do Rio de Janeiro e de outros estados (São Paulo, Espírito Santo, Pernambuco), escreveu prefácios de livros e publicou nos referidos al-

2 Narcisa Amália Campos.

3 Obra reeditada pela Fundação Biblioteca Nacional (Brasil), em 2018. 
manaques. No jornalismo e em conferências, Narcisa Amália foi uma militante das causas femininas e denunciou as dificuldades de as mulheres se dedicarem aos estudos e à escrita literária em um país que trata "com desdém criminoso a educação intelectual da mulher" (AMÁLIA, apud REIS, 1949, p.76).

Narcisa Amália foi a primeira mulher a assumir a profissão de jornalista, tendo-se destacado por ideias e assuntos à frente de seu tempo e, sobretudo, pela luta por dar voz à mulher (PAIXÃO, 200o, p.536). Em $O$ Garatuja, a escritora fez a seguinte indagação: "como há de a mulher revelar-se artista se os preconceitos sociais exigem que o seu coração cedo perca a probidade, habituando-se ao balbucio de insignificantes frases convencionais?” (Apud ELEUTÉRIO, 2005, p.120). Outrossim, vale destacar aqui um artigo, publicado em $D e-$ mocratema, de Amália intitulado A mulher no séc. XIX, prosa em defesa dos direitos da mulher, de 1882, em que ela, através de discurso veemente e irônico, denuncia os limites impostos às mulheres no que se refere à formação educacional, cultural e profissional. Vejamos um excerto publicado desse artigo:

A educação da mulher! Mas tem a mulher por acaso necessidade de ser educada? Para quê? Cautela! A mulher representa o gênio do mal sob uma forma mais ou menos graciosa e cultivar a sua inteligência seria fornecer-lhe novas armas para o mal. Procuremos antes torná-la inofensiva por meio da ignorância. Guerra, pois, à inteligência feminil! (AMÁLIA apud RAMALHO, 2012, p.135-156)

O volume Narcisa Amália: 1852-1924, em apreço nesta resenha, conta com "Prefácio” de Isabel Cruz Lousada e Vania Pinheiro Chaves, que explicam aos leitores os critérios adotados para publicações de estudos e antologias para a Série Senhoras do almanaque. Esse novo volume da coletânea, além de divulgar uma escritora que colaborou com o Almanaque de lembranças, em diferentes momentos, dá a conhecer uma mulher avançada para sua época, que assumiu 
posicionamentos políticos fundamentais para mudanças de mentalidade na sociedade brasileira e consequentes alterações do status quo. Nos seus poemas, ela denuncia a escravidão, a opressão e os preconceitos, bem como dirige críticas e expressa indignação contra a ordem vigente, atitude rara e corajosa, sobretudo vinda de jornalista em momento histórico em que, raramente, as mulheres manifestavam publicamente as suas opiniões políticas e seus valores sociais.

Organizado por Anna Faedrich - pesquisadora que já havia sido responsável pela reedição de Nebulosas, pela Fundação Biblioteca Nacional do Rio de Janeiro -, o volume em análise abre com um “Estudo" sobre a escritora fluminense, a que se justapõe uma Tábua Cronológica de sua biobibliografia. Nesse “Estudo”, Faedrich debruça-se sobre a biografia da autora e aponta fatores que contribuíram para a sua formação cultural, como o fato de o pai ter sido professor, jornalista e poeta, e a mãe, professora. Narcisa alfabetizou-se em casa aos quatro anos, estudou música, latim e francês e, jovem ainda, iniciou a tradução de obras em francês, entre as quais a da Histoire de ma vie, de George Sand, escritora francesa que adotou esse nome masculino, para conseguir ser publicada na França do século XIX. Faedrich sublinha também os escritores brasileiros com os quais Narcisa estabeleceu intercâmbios literários e destaca poetas que a teriam admirado, entre os quais Raimundo Correia, Damasceno Vieira e Fagundes Varela. Traz igualmente importantes informações sobre a recepção crítica da escritora fluminense, não só dos críticos que acolheram e reconheceram a qualidade literária de sua produção poética, como ainda dos que contestaram a sua inteligência e agudeza de espírito.

Na Antologia dos textos de Narcisa Amália, a organizadora reúne os poemas editados no Almanaque de lembranças, com alguns dos publicados em Nebulosas e em outras fontes, além de duas cartas e de um ensaio crítico da escritora fluminense sobre o livro Crepúsculos, da poeta gaúcha Amália Figueiroa. Esta edição traz também 
"Bibliografia ativa de Narcisa Amália" e "Bibliografia passiva", fontes importantes para pesquisadores desenvolverem novos estudos sobre autora de Nebulosas. Destaco, finalmente, nos Anexos, fotografias de Narcisa Amália e de Narcisa com a sua filha, Alice Violeta, bem como cópia de recortes de jornais com seus textos impressos e de manuscritos disponíveis na Fundação Biblioteca Nacional.

O volume Narcisa Amália:1852-1924 revela a importância do Projeto de Pesquisa desenvolvido no CLEPUL pelo Grupo de Investigação “Brasil: literatura, memória e diálogos com Portugal”, coordenado pela Professora Doutora Vania Pinheiro Chaves, que conta com a parceria da Professora Doutora Isabel Cruz Lousada, do CICS.NOVA, e com o apoio da Biblioteca Nacional de Portugal, que em conjunto estão a retirar da sombra grandes escritoras de língua portuguesa, inviabilizadas pela falta de oportunidade de atuarem nos meios letrados e de verem seus textos editados. Nesse sentido, o Almanaque de lembranças, o Almanaque de lembranças luso-brasileiro e o Novo almanaque de lembranças luso-brasileiro, nos seus 82 anos de circulação, desempenharam um papel relevante por abrir espaços para essas escritoras, muitas das quais só tiveram essa única oportunidade de publicar seus poemas, crônicas, enigmas e outros tipos de textos. A série Senhoras do almanaque desenvolve um trabalho de arqueologia literária ao dar visibilidade à criação literária que foi condenada ao apagamento e, desse modo, consegue reverter esse destino obscuro da escrita feminina, trazendo à luz uma história não narrada pela historiografia literária.

RECEBIDO: 06/09/2021

Aprovado: 15/09/2021

\section{REFERÊNCIAS}

ELEUTÉRIO, Maria de Lourdes. Vidas de romance. As mulheres e o exercício de ler e escrever no entresséculos (1890-1930). Rio de Janeiro: Topbooks, 2005. 
FAEDRICH, Anna (org,) Narcisa Amália: 1852-1924. Estudo, antologia e bibliografia. Lisboa: Biblioteca Nacional de Portugal; CLEPUL (Centro de Literaturas e Culturas Lusófonas e Europeias); CICS.NOVA (Centro Interdisciplinar de Ciências Sociais), 2020.

MACHADO, Ubiratan. A vida literária no Brasil durante o romantismo. Rio de Janeiro: Editora da Universidade do Estado do Rio de Janeiro, 2001.

PAIXÃO, Sylvia Perlingeiro. "Narcisa Amália”. In: MUZART, Zahidé Lupinaci. Escritoras brasileiras do século XIX. Florianópolis: Editora Mulheres; Santa Cruz do Sul: EDUNISC, 2000, v.1, p. 534-552.

RAMALHO, Cristina. "Retratos do cotidiano: a crônica em três vozes". Leitura, n. 49, Maceió, p.135-156, jan/jun. 2012.

REIS, Antônio Simões dos. Narcisa Amália. Rio de Janeiro: Simões, 1949.

\section{MiNicuRRÍculo}

Ana Maria Lisboa de Mello é licenciada em Letras (Português-Francês) pela Universidade Federal do Rio Grande do Sul, mestre e doutora em Teoria da Literatura pela Pontifícia Universidade Católica do Rio Grande do SUL (PUCRS). Fez estágios de Pós-doutoramento no Centre de Recherches sur l'imaginaire, na Université Stendhal, Grenoble III (1996), com bolsa do CNPq, na Université Sorbonne Nouvelle - Paris II (2004), com bolsa CAPES, e na University of Toronto (2014), com bolsa CAPES. Foi professora da UnB, da UFRGS, da PUCRS e, em 2017, vinculou-se ao PPGLEN, do Instituto de Letras da UFRJ. É colaboradora no CLEPUL-ULisboa e bolsista de Produtividade em Pesquisa do CNPq. 